\title{
A STABLE CUVETTE OF HIGH SENSITIVITY FOR INDICATOR DILUTION CURVES
}

\author{
BY \\ JOHN NORMAN \\ From the Institute of Cardiology \\ Received June 16, 1958
}

The increasing use of indicator dilution techniques for both qualitative(Swan et al., 1953; Broadbent and Wood, 1954) and quantitative (Swan et al., 1956) assessment of central shunts and for cardiac output estimations (Hamilton et al., 1948) has emphasized the need for dye monitoring systems of considerable stability and sensitivity. For the accurate calculation of the cardiac output and the ready assessment of intracardiac shunts during cardiac catheterization, systems for this purpose should possess these characteristics: (a) recorder deflection proportional to whole blood dye concentration, (b) zero drift through the relevant time, (c) high sensitivity, (d) long-term maintenance of spectral sensitivity, and (e) directly written deflections of adequate size for accurate extrapolation.

Most cuvettes previously described for the continuous recording of dye concentrations in whole blood have used vacuum or gas-filled multiplier photo-cells as the sensitive element, necessitating high voltage supplies and high gain amplifiers in order to produce an acceptable signal level (Friedlich et al., 1950; Falholt and Kaiser, 1955; Shadle et al., 1953). The few instruments using barrier layer cells have in general employed low intensity light sources, often consisting of a series of flash-lamp bulbs, and unsealed barrier layer cell assemblies (Nicholson et al., 1951).

A criticism of many of these methods has been that the current change in response to the increasing concentration of dye is extremely small, and further amplification is necessary before this output is sufficient to operate the recorder amplifier itself. A consideration of the many factors affecting the final stability of whole blood cuvettes has shown that a large increase in the current output change, in response to a given increase in dye concentration, effects the most significant improvement in stability. Since the area of selenium cell that can be exposed to the light source is limited, such an improvement in performance can only be obtained by increasing the light intensity or the sensitivity of the selenium cell itself. Although selection of selenium cells may produce units that, area for area, have outputs of up to 1.3 times the mean output of the batch, such a small increase in sensitivity is unlikely to be of any real advantage. An increase in the light intensity however is easily obtained, and produces an increase in output current which can be of very real value. Since both the red cell and the infra-red cell are not only sensitive to light but also to temperature, the use of higher light levels makes some form of thermal equilibration essential. The achievement of a constant temperature state is probably also necessary in instruments using only low intensity light sources.

Using compressed air from a cylinder, flow rates of 17 litres a minute produce an air temperature at the cylinder outlet of $8^{\circ} \mathrm{C}$., and simultaneous seven point recordings of the temperature at various parts of the cuvette described, show a rise of only $4 \cdot 5^{\circ} \mathrm{C}$. above the ambient temperature at the photocell faces during a period of 60 minutes. Once this temperature is reached, maximum variations over 60 minutes are approximately $1^{\circ} \mathrm{C}$. A thermal stability of this order would appear to be essential in an instrument for quantitative use.

Were it not for the disadvantages of the high tension supply system associated with photomultiplier photo cells, these units would undoubtedly be the cells of choice for whole blood cuvettes, for barrier layer cells are extremely sensitive to many materials in the vapour phase, and difficulties 
are often experienced with the spring devices normally used for electrical contact. Contact difficulties of this nature give rise to short-term intermittency (flicker), while the deterioration of the sensitive surface of the photo-voltaic cell itself causes a rapid loss in output and an alteration of the spectral sensitivity. In the present instrument these well known disadvantages of barrier layer cells have been completely eliminated by the use of pairs of cells embedded in Araldite. The infra-red and red cells are completely enclosed in the hard resin, behind a glass window. The leads are soldered to the sprayed-on contact surfaces of the photo-cells and are brought to terminals embedded in the resin around the cells. This gives a water-proof and chemical-proof assembly where there can be no possibility of the contacts being insecure, even when subject to severe vibration. This method also has the advantage that the relative position of the two cells is fixed permanently, and they can be handled as a single mechanically robust unit.

Construction. The cuvette (Fig. 1) is formed from black perspex, and consists of a block containing the light source (A), screwed permanently to the lens block (B). A fixed spacer (C) compensates for the thickness of the cuvette slot itself (D) and the mask (E). The red and infra-red filters $\left(F^{\prime}, F^{\prime \prime}\right)$ are recessed into the face of the photo-cell block $(G)$ which contains the embedded assembly of barrier layer cells $(\mathrm{H})$. Air is circulated through the lamp housing and thence over the lens, blood cell and filter faces, by means of the Luer entries at the side of the lamp housing (K and L). Connection to the two photo-cells is by means of a flexible link (M).

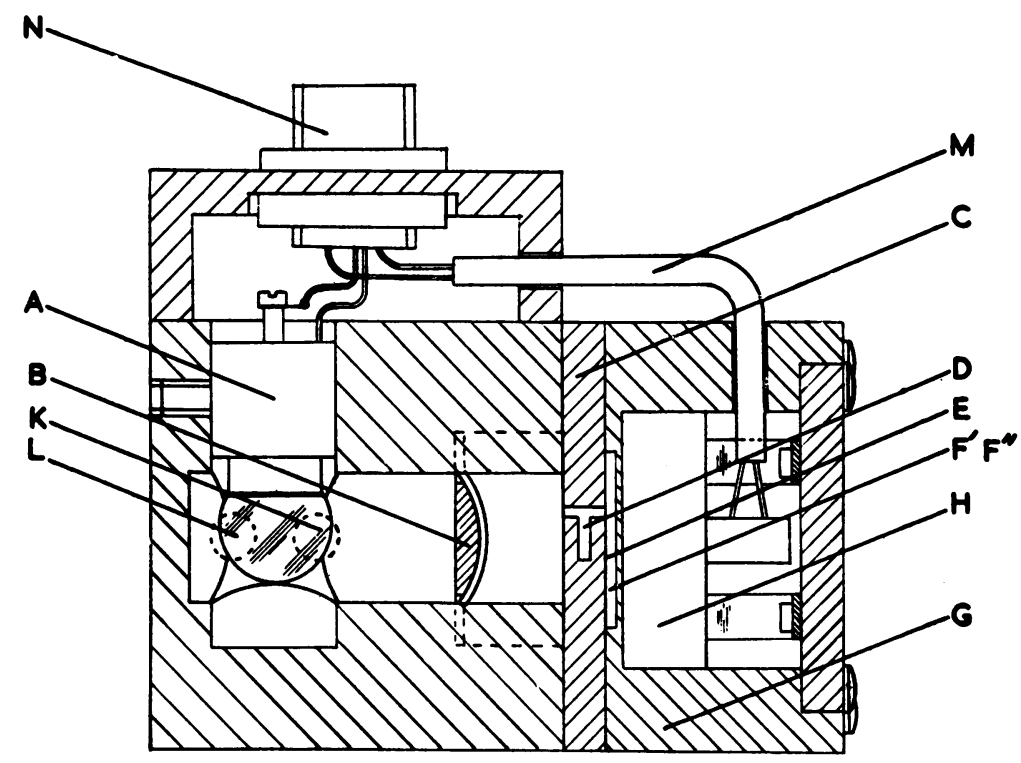

FIG. 1.-Constructional details of cuvette. For explanation see text.

The light source is a 6 volt, 6 watt bulb run at 8 volts; its low tension supply, together with the output from the photo-cells, is formed into a single screened cable with the air lines attached, joining the cuvette at a Mk IV socket $(\mathrm{N})$.

The output from the photo-cells is fed into a balancing network (Fig. 2) fitted with coarse and fine balance controls, stepped gain control, and a dye selector switch. From this matching unit the output is taken directly to a Honeywell-Brown Chart recorder,

Polythene tubing (O.D. 0.120 inch: I.D. 0.080 inch) is used for the blood cell itself, and when in place in the clear perspex slot it assumes a roughly elliptical shape (major axis $0.160 \mathrm{inch}$, minor axis $0 \cdot 068$ inch). The tubing terminates in male and female Luer adaptors. A metal stem attached to the perspex block forming the lamp housing facilitates the mounting of the unit in any desired position by means of retort stand clamps (Fig. 3). 
Performance. In common with all whole blood cuvettes the unit shows a change in output for changing flow rates when the flow of blood through it falls below a critical minimum. In the instrument described, changes in flow rates when the basic flow is in excess of $20 \mathrm{ml}$. a minute have no effect on stability.

The maximum sensitivity is of the order of $0.4 \mathrm{mg}$. Evans Blue $/ 1$.(whole blood) $/ \mathrm{cm}$. deflection using the 6 watt light source; an increase where necessary can be easily effected by an increase in

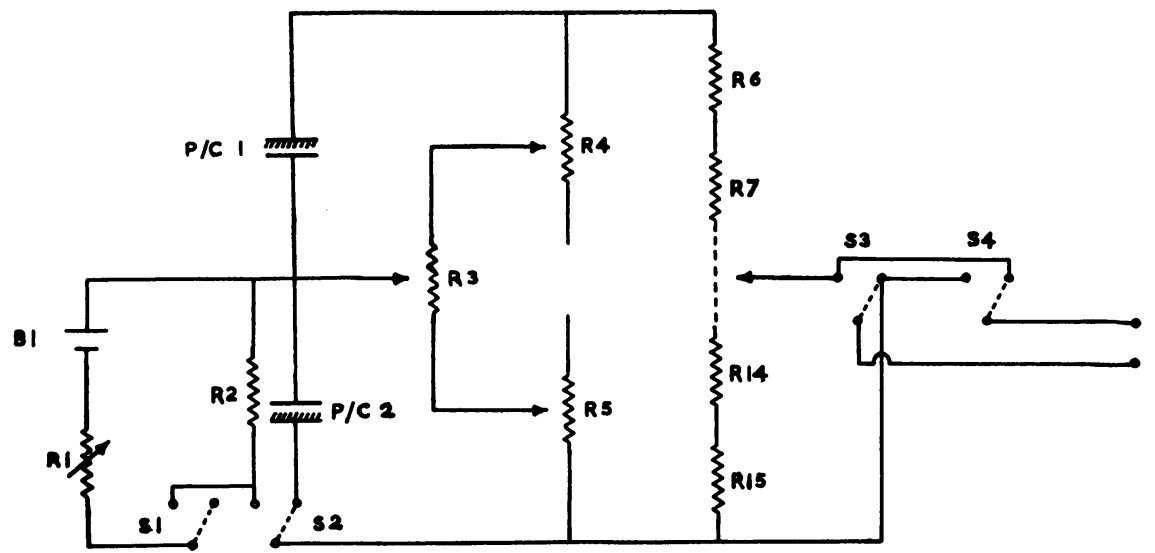

FIG. 2.-Circuit diagram of matching unit. The switches, S1, S2, S3, S4, are shown in the Evans Blue or Indigo Carmine position. The alternative position effects the circuit modifications necessary when using Cardio-Green. $\mathrm{R} 1=500 \Omega . \quad \mathrm{R} 2=10 \Omega . \quad \mathrm{R} 3=1 \mathrm{k}$ Helical $\mathrm{R} 4, \mathrm{R} 5=10 \mathrm{k}$, 10k (Ganged). R6 $\mathrm{R} 15=500 \Omega$. S1, S2, S3, S4, =S.P.D.T. (Ganged). $\mathrm{P} / \mathrm{C} 1=$ Infra Red Cell. $\mathrm{P} / \mathrm{C} 2=$ Red Cell. $\mathrm{B} 1=1 \cdot 5 \mathrm{~V}$ Dry Cell.

wattage of the source, since the density of the total light path is such that the light intensity seen by the photo-cell is still relatively low.

The application of a positive pressure of two atmospheres to the blood filled cuvette produces a deflection equivalent to $0.5 \mathrm{mg}$. Evans Blue/l.(whole blood); the cuvette path elasticity is seen to be such that arterial pulsation artefacts as a result of fluctuating pressure changes are negligible.

The stability of the instrument has been confirmed by the use of a constant displacement pump drawing fully oxygenated whole blood through the light path. Even cell distribution was ensured by

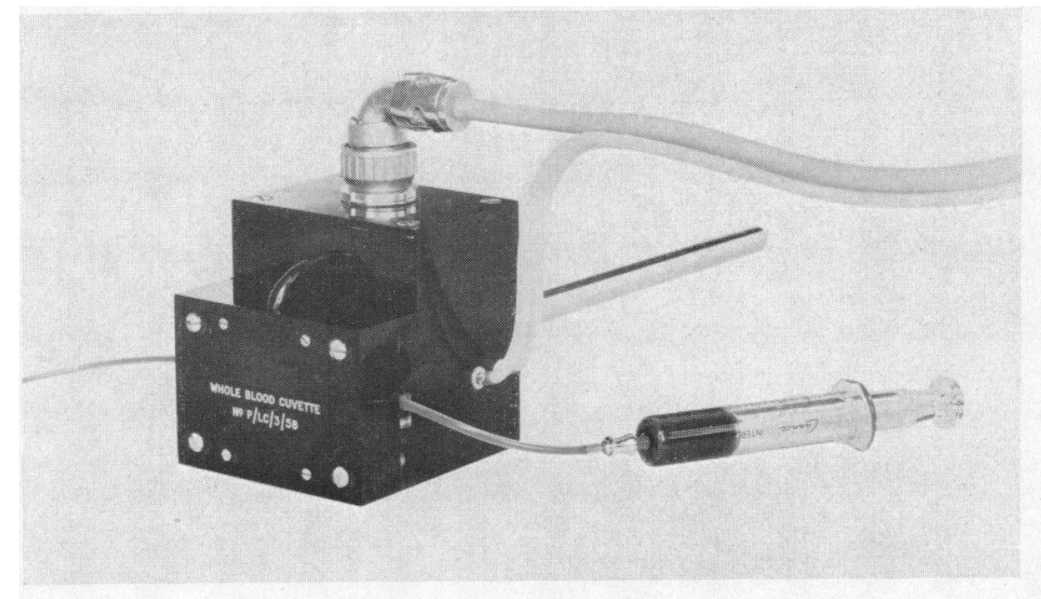

FIG. 3.-Cuvette with air lines attached. 
the use of a mixer. Maximum deviation during a 10 minute flow period is equivalent to $0 \cdot 1 \mathrm{mg}$. Evans Blue/1. (whole blood).

The relationship between final deflection and Evans Blue concentration is essentially a linear one up to the maximum concentration likely to be found after repeated dye injections.

Comment. Since the unit behaves as an oximeter, arterial oxygen saturation changes related to respiratory phase in cyanotic patients may deform the baseline. To overcome this difficulty a position is provided on the dye selector switch which so modifies the circuit that use may be made of one of the tricarbo-cyanine group of dyestuffs such as Cardio-Green, the maximum spectral absorption of which occurs at 800 millimicrons, a wave-length at which oxyhæmoglobin and reduced hæmoglobin transmit light equally (Fox et al., 1957; Kramer and Ziegenrücher, 1957). This circuit modification removes the red cell from the input network, and replaces it with a small fixed voltage for balancing purposes only. The polarity of the infra-red cell, on which the green density is measured, is also reversed, in order that the dye curve may be inscribed in the orthodox manner.

\section{SUMMARY}

A simple, linear cuvette system is described. The disadvantages of barrier layer cells, particularly as far as their long-term stability is concerned, have been largely overcome by the use of sealed pairs of red and infra-red cells. Stability is further improved by maintaining thermal equilibrium of the sensitive unit by the use of a stream of cooling air.

A high intensity light source and plano-convex lens system provide for a large output from the photo-cells, thus improving the 'signal/noise' ratio, and allowing the output to be fed directly to the recorder.

The sensitivity of the instrument is such that central injections of only $5 \mathrm{mg}$. of Evans Blue or equivalent amounts of indigo-carmine or Cardio-Green will produce deflections of up to $25 \mathrm{~cm}$. on a wide chart recorder.

A simple matching unit includes a dye selector switch, which enables the sensitivity of the cuvette to all three commonly used dyes to be fixed at the same level, and also effects the circuit changes that are necessary when using Cardio-Green.

Linearity and stability are more than adequate for quantitative work.

I wish to thank Mr. L. M. Clarke, Senior Technician at the Institute of Cardiology for his help in the construction of this apparatus, and Mr. P. Marcus of Megatron Ltd. for his invaluable assistance and advice. Megatron Ltd. manufactured the embedded cells used in the cuvette. The complete dye assembly is available from Messrs. New Electronic Products Ltd.

\section{REFERENCES}

Broadbent, J. C., and Wood, E. H. (1954). Circulation, 9, 890.

Falholt, W., and Kaiser, E. (1955). Circ. Res., 469, 3.

Fox, I. J., Brooker, L. G. S., Heseltine, D. W., and Essex, H. E. (1957). Abstr. Fed. Proc., 16, 39.

Friedlich, A., Heimbecker, R., and Bing, R. J. (1950). J. appl. Physiol., 3, 12.

Hamilton, W. F., Riley, R. L., Attyah, A. M., Cournand, A., Fowell, D. M., Himmelstein, A., Noble, R. P., Remington, J. W., Richard, D. W., Wheeler, N.C., and Witham, A. C. (1948). Amer. J., Physiol., 153, 309.

Kramer, Kurt., and Ziegenrücker, Gerd. (1957). Klin. Wschr., 35, 468.

Nicholson, J. W., 111, Burchell, H. B., and Wood, E. H. (1951). J. Lab. clin. Med., 37, 353.

Shadle, O. W., Ferguson, T. B., Gregg, D. E., and Gilford, S. R. (1953). Circ. Res., 1, 200.

Swan, H. J. C., Hetzel, P. S., and Wood, E. H. (1956). Circulation, 14, 22.

-, Zapata-Diaz, J., and Wood, E. H. (1953). Circulation, 8, 70. 